$$
\text { CONF- } 9606116--86
$$

\title{
Calculating the Shrapnel Generation and Subsequent Damage to First Wall and Optics Components for the National Ignition Facility
}

R. E. Tokheim, L. Seaman, T. Cooper, B. Lew, D. R. Curran, J. Sanchez, A. Anderson, M. Tobin

This paper was prepared for submittal to the Proceedings of the American Nuclear Society, 12th Topical Meeting on the Technology of Fusion Energy

Reno, NV

June 16-20, 1996

August 6, 1996

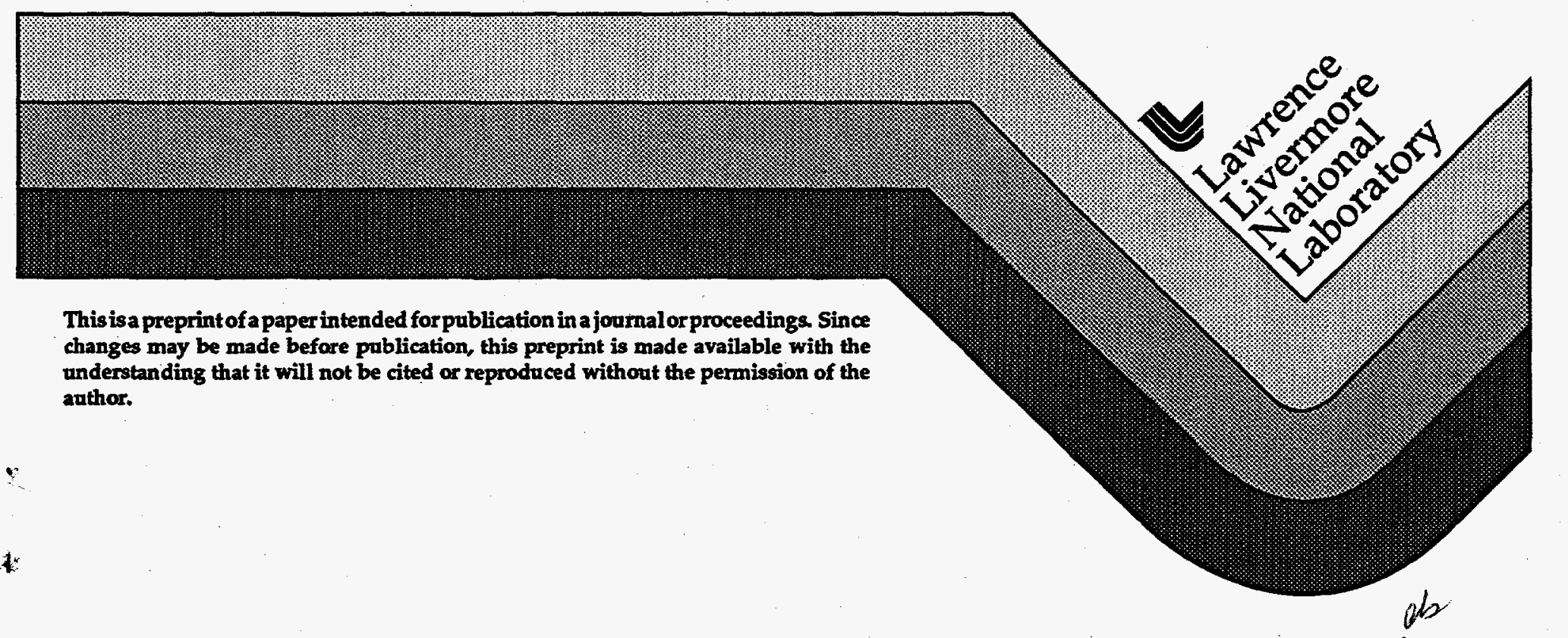




\section{DISCLAIMER}

This document was prepared as an account of work sponsored by an agency of the United States Government. Neither the United States Government nor the University of California nor any of their employees, makes any warranty, express or implied, or assumes any legal liability or responsibility for the accuracy, completeness, or usefulness of any information, apparatus, product, or process disclosed, or represents that its use would not infringe privately owned rights. Reference herein to any specific commercial product, process, or service by trade name, trademark, manufacturer, or otherwise, does not necessarily constitute or imply its endorsement, recommendation, or favoring by the United States Government or the University of California. The views and opinions of authors expressed herein do not necessarily state or reflect those of the United States Government or the University of California, and shall not be used for advertising or product endorsement purposes. 


\section{DISCLAMMER}

Portions of this document may be illegible in electronic image products. Images are produced from the best available original document. 


\section{CALCULATING THE SHRAPNEL GENERATION AND SUBSEQUENT DAMAGE TO FIRST WALL AND OPTICS COMPONENTS FOR THE NATIONAL IGNITION FACILITY}

R. E. Tokheim, L. Seaman, T. Cooper, B. Lew, and D. R. Curran

SRI International

333 Ravenswood Ave.

Menlo Park, CA 94025-3493

(415) 326-6200

\section{ABSTRACT}

The purpose of this work is to computationally assess the threat from shrapnel generation on the National Ignition Facility (NIF) first wall, final optics, and ultimately other target chamber components. Shrapnel is defined as material that is in a solid, liquid, or clusteredvapor phase with sufficient velocity to become a threat to exposed surfaces as a consequence of its impact. Typical NIF experiments will be of two types, low neutron yield shots in which the capsule is not cryogenically cooled, and high yield shots for which cryogenic cooling of the capsule is required. For non-cryogenic shots, shrapnel would be produced by spalling, melting, and vaporizing of "shine shields" by absorption and shock wave loading following $1-\omega$ and 2- $\omega$ laser radiation. For cryogenic shots, shrapnel would be generated through shock wave splitting, spalling, and droplet formation of the cryogenic tubes following neutron energy deposition. Motion of the shrapnel is determined not only by particle velocities resulting from the neutron deposition, but also by both $\mathrm{x}$-ray and debris loading arising from explosion of the hohlraum. Material responses of different target area components are computed from one-dimensional and two-dimensional stress wave propagation codes. Well

\author{
J. Sanchez, A. Anderson, and M. Tobin \\ Lawrence Livermore National Laboratory \\ P. O. Box 808 \\ Livermore, CA 94551 \\ (510) $422-1100$
}

developed rate-dependent spall computational models are used for stainless steel spall and splitting. Severe cell distortion is accounted for in shine-shield and hohlraum-loading computations. Resulting distributions of shrapnel particles are traced to the first wall and optics and damage is estimated for candidate materials. First wall and optical material damage from shrapnel includes crater formation and associated extended cracking.

\section{INTRODUCTION}

The National Ignition Facility (NIF) is a proposed U.S. Department of Energy inertial confinement laser fusion facility. The NIF will operate by focusing 192 laser beams onto a mm-sized deuterium-tritium capsule located at the center of a spherical target chamber having a design radius of 5 meters. Its mission is to achieve inertial confinement fusion (ICF) ignition, access physical conditions in matter of interest to nuclear weapons physics, provide an above ground simulation capability for nuclear weapons effects testing, and contribute to the development of inertial fusion for electrical power production.

The preliminary indirect-drive cryogenic target design for capsule shots producing yield 
includes small capillary cryogenic tubes of stainless steel leading to the hohlraum. These are used to remove heat from the target assembly due to wall thermal loading and tritium decay. To support diagnostics requirements, additions to the basic non-cryogenic target design such as "shine shields" may be required, increasing the total mass of the target assembly. Shrapnel generation has affected Nova operations and with the increased mass of targets, increased laser energy, and increased fusion yields for NIF, concern has been raised as to the threat to the NIF first wall protection system, the target positioner, and the final optics components.

In this paper we begin our investigation of shrapnel damage by computing what we believe will be the worst case scenarios for first wall and optics debris-shield threats and damage, namely, the $20 \mathrm{MJ}$ yield shot with the cryogenic configuration, and the no-yield 1.8 MJ non-cryogenic shine-shield configuration.

\section{SHRAPNEL FROM CRYOGENIC TUBES FOR 20MJ SHOTS}

A. Description of shrapnel generation from target assembly

The potential threat considered here consists of debris and $x$ rays from the gold hohlraum ( $1.0 \mathrm{~cm}$ dia., $0.6 \mathrm{~cm}$ length, $30 \mu \mathrm{m}$ thickness, $0.30 \mathrm{~cm}$ laser entrance hole) and stainless steel shrapnel originating from the cryogenic tubes $(0.125 \mathrm{~mm} \mathrm{ID}, 0.2 \mathrm{~mm} \mathrm{OD})$, which are filled with liquid $\mathrm{He}$ at $10 \mathrm{~K}$ and $200 \mathrm{~atm}$ as sketched in Fig. 1. Partition of point source energy is $16 \mathrm{MJ}$ for neutrons, $2 \mathrm{MJ}$ for $x$ rays external to the hohiraum (3.8 MJ total), and $2 \mathrm{MJ}$ for debris. The shrapnel is created as the tubes expand due to neutron heating, and the shrapnel is then accelerated further by absorption of hohlraum $x$ rays and by the debris "wind" from the hohlraum. X-ray

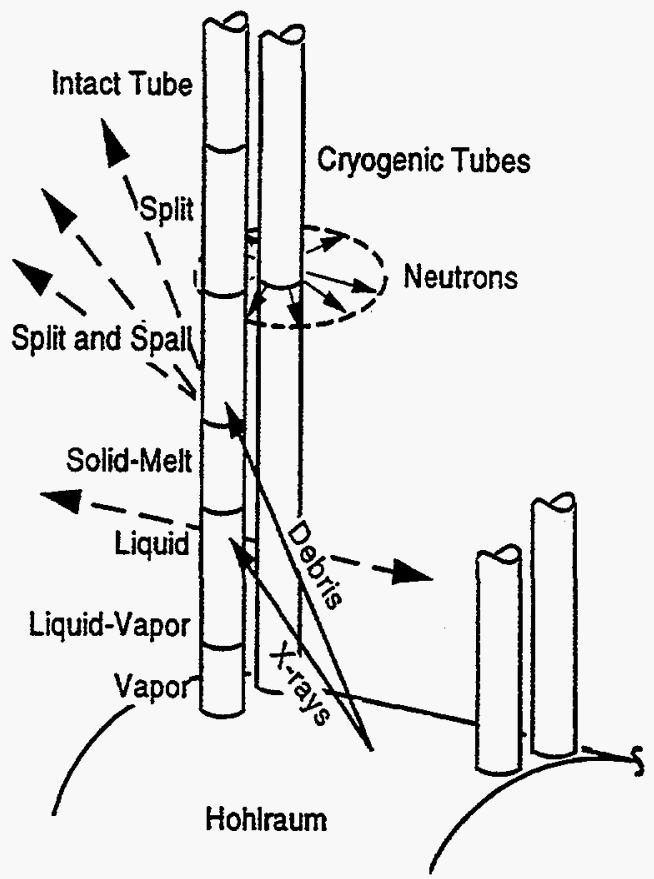

Figure 1. Schematic of hohlraum and cryogenic tubes for yield shots.

loading will result in an impulse in the direction of the hohlraum axis for cryotubes assumed to be in plane of the hohlraum axis. Debris loading will be radial from the point source. Neutron heating in the cyrotubes decreases with distance from the source. Particle velocities corresponding to deposited energies that cause expansion of the tubes are shown in Fig. 2. Below melt energy spall occurs, and at somewhat lower energies split and spall, and at even lower energies, splitting alone. Fragment distributions were determined for neutron energies based on radial PUFF (stress wave code) nucleation and growth spall and circumferential Mott ${ }^{1}$ fragmentation criteria computations. Above melt, droplet formation is assumed to follow Grady's formula, ${ }^{2}$ relating diameter $D$ to surface tension $\gamma$, density $\rho$, and strain rate d $\boldsymbol{d} / \mathrm{dt}$ :

$$
\mathrm{D}=\left(48 \gamma^{\prime} \rho(\mathrm{d} \varepsilon / \mathrm{dt})^{2}\right)^{1 / 3}
$$




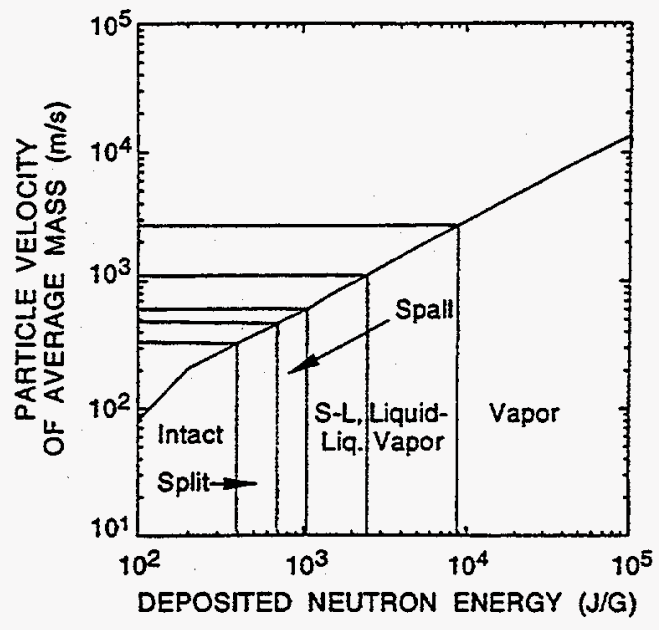

Figure 2. Particle velocity in cysotubes as a function of deposited neutron energy.

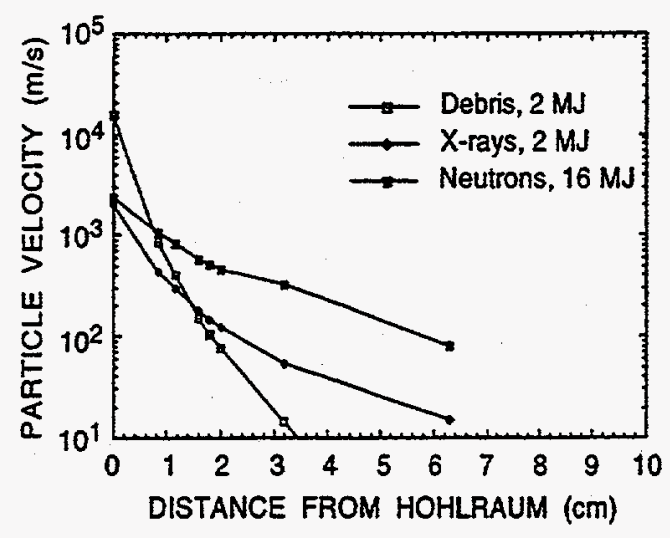

Figure 3. Particle velocities in stainless steel cryotubes for $20 \mathrm{MJ}$ case.

Figure 3 shows particle velocities from $x$ rays, hohlraum debris, and neutrons. Debris velocities are dominant near the hohlraum.

\section{B. Threat and damage at first wall and op- tics components}

Fig. 4 shows treatment of cryotube breakup and projection onto chamber wall locations. Each sector has its own particle size distribution. Computed mass density and mean particle radius of shrapnel at the first wall are shown in

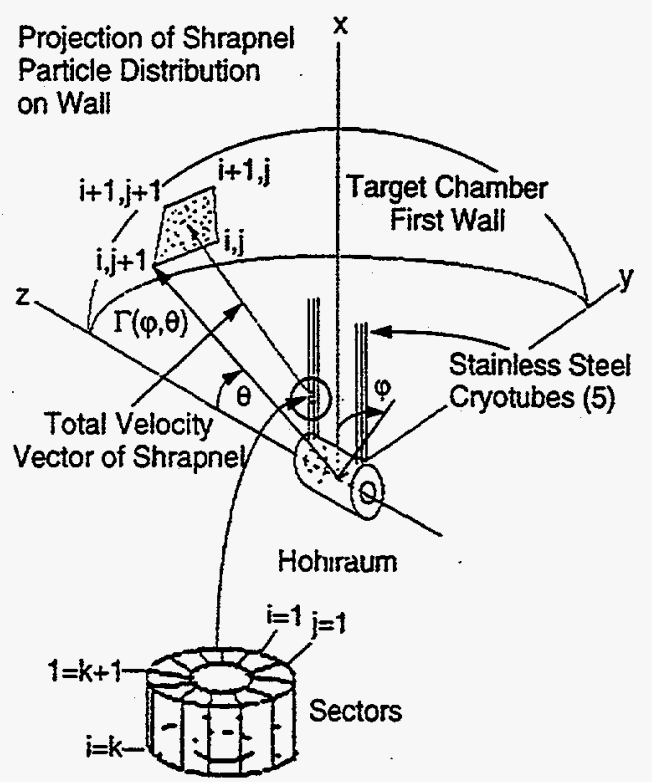

Figure 4. Configuration for NIF yield shot showing treatment of cryogenic tube break-up and shrapnel/debris projection onto target chamber first wall.

Figs. $5 a$ and $5 b$. Computed relative areal damage based on the cratering algorithm described in Part IV is shown in Fig. 6a for $\mathrm{B}_{4} \mathrm{C}$ first wall, and in Fig. $6 \mathrm{~b}$ for fused silica optics debris shields ( $6.75 \mathrm{~m}$ radius from source). The current chamber design geometry will tend to concentrate the larger particles on the beltline away from the debris shields, and to concentrate the smaller particles on the debris shields. Maximum damage here tends to focus near $\theta=73 \mathrm{deg}$ and small $\phi$ angles, at 5 to $7 \mathrm{~km} / \mathrm{s}$, for vapor-cluster 1 to $10 \mu \mathrm{m}$ particles. The calculated removal layer of $B C$ will help determine the durability of the first wall coating. A greater threat to the first wall is believed to arise from the larger shrapnel particles $(150 \mu \mathrm{m})$ impacting at about $400 \mathrm{~m} / \mathrm{s}$, because of their greater damage depths. However, the debris shield may suffer the most from the high velocity small particles because a shallow depth of damage is believed to be sufficient to obscure the shield. The acceptable depth of 


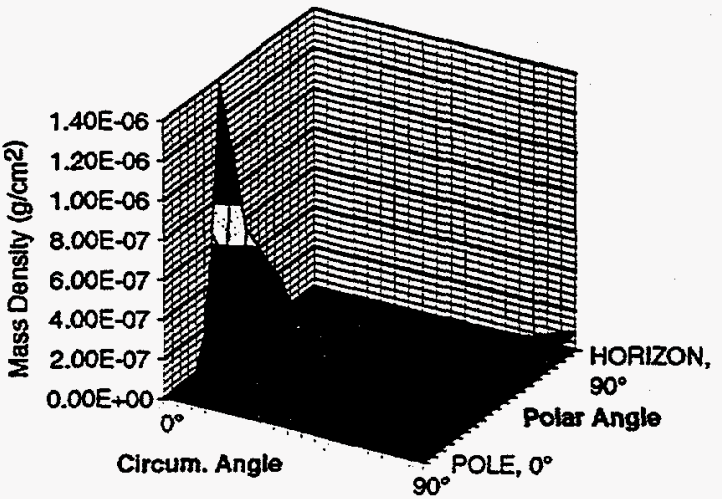

(a)

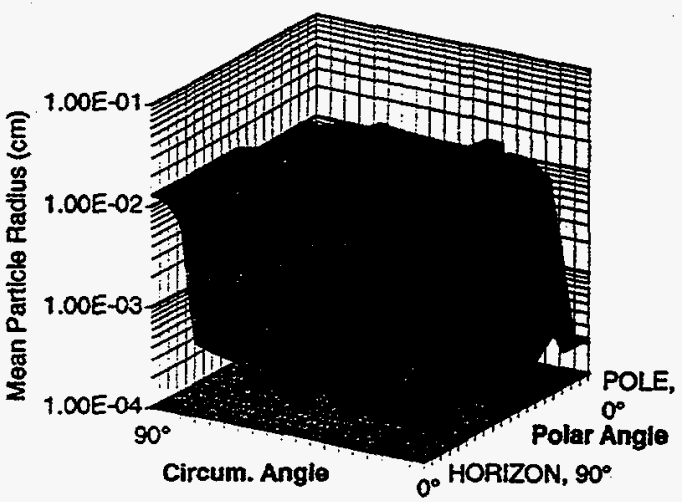

(b)

Figure 5. Computed stainless steel schrapnel at first wall location from cryogenic tubes in $20 \mathrm{MJ}$ NIF shot.

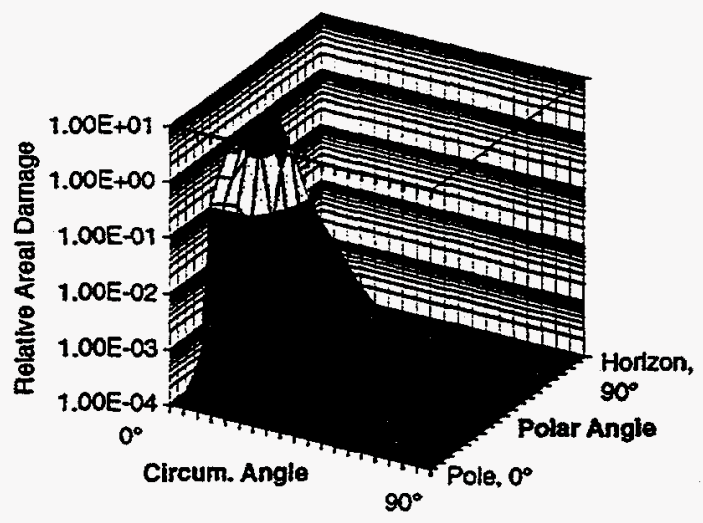

(a) First Wall $\left(\mathrm{B}_{4} \mathrm{C}\right)$

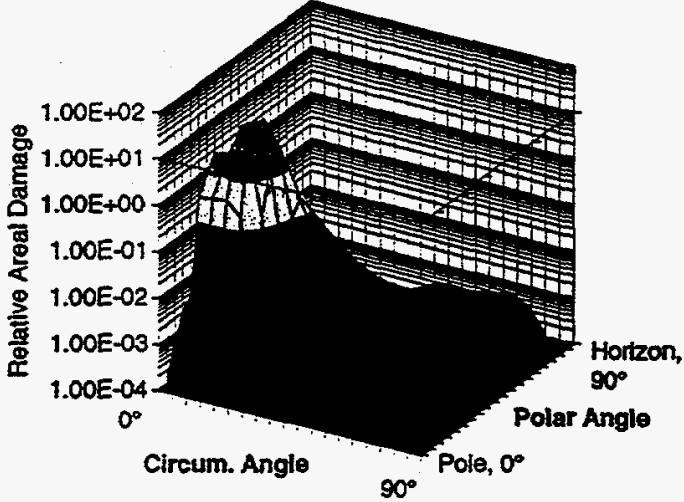

(b) Debris shield location (FS)

Figure 6. Computed schrapnel damage from 20 MJ NIF shot based on extrapolated algorithms.

removal has yet to be measured. Only a few hundred of the larger shrapnel particles will be producedbut $10^{7}-10^{8}$ of the smaller particles will be produced; hence the large estimated damage of the latter, based on our extrapolated algorithm.

\section{SHRAPNEL GENERATION FROM $1.8 \mathrm{MJ}$ NON-CRYOGENIC TARGET DESIGN INCLUDING SHINE SHIELDS}

A. Description of shrapnel generation from target assembly
In this case the threat consists of shrapnel from the gold hohlraum and copper shine shields (see Fig. 7). The copper disk shine shields are irradiated with 1- $\omega$ and 2- $\omega$ laser light, while the 3- $\omega$ light enters the hohlraum. The spatial variation of the former was determined and combined loading cases were chosen at certain radii as shown in Fig. 8, to be interpolated for initial loading conditions. Two-dimensional computations were made with our two-dimensional free-Lagrangian code (L2D) for the hohlraum and shine shields. An $x$-ray mixed black-body point source was assumed for computing the effect of transmitted $x$ rays through 


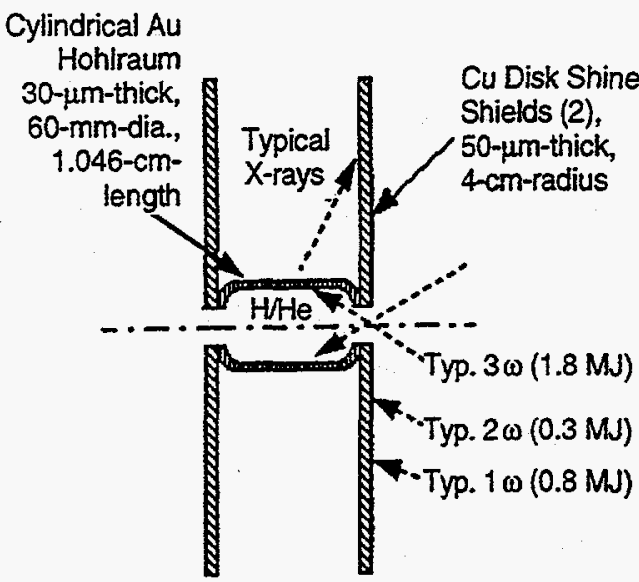

Figure 7. Configuration for $1.8 \mathrm{MJ}$, no-yield case with shine shields.

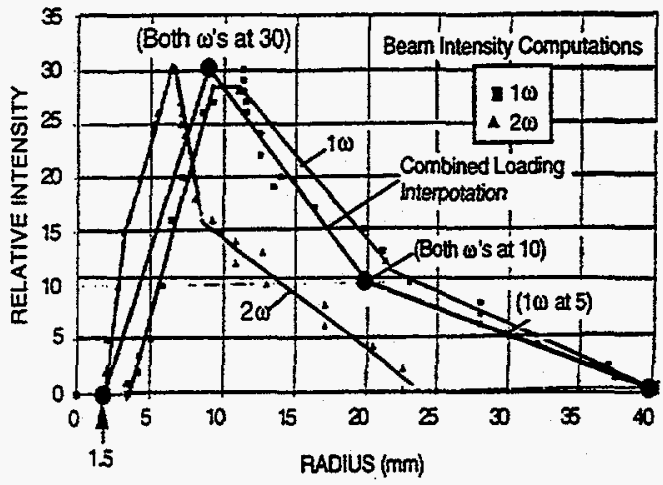

Figure 8. Shine shield loading interpolations points based on irradiance of $1-\omega(1.06 \mu \mathrm{m})$ and $2-\omega(0.53 \mu \mathrm{m})$ laser light used for shock wave computaitons.

the hohlraum to the inside of the shine shields. The one-dimensional HYADES ${ }^{3}$ radiation transport code was used up to 20 ns to obtain initial loading conditions (based on the combined loading cases described above) for L2D two-dimensional stress wave computations. The velocity field computations from L2D, maintaining material phase boundaries during advection) given in Fig. 9 show gold with the highest velocities (upwards of $10 \mathrm{~km} / \mathrm{s}$ through the laser entrance hole), and lower velocities for the copper; both

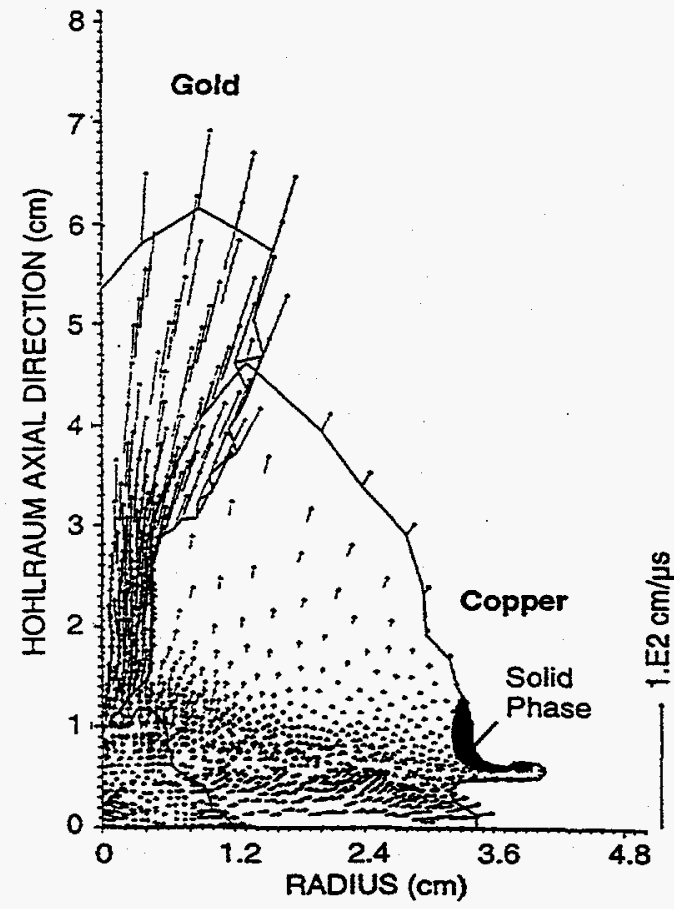

Figure 9. Velocity field at 112 ns for no-yield configurations with shine shields (phase boundaries maintained).

materials together spray material largely along the hohlraum axis, but also at all other polar angles.

B. Threat and damage at first wall and optics components

We computed the effects of the computed explosion of hohlraum and shine shields by tracing cells of material to the wall using the velocity field information at 112 ns. Fig. 10 shows the resulting mass distribution at the first wall: all of the gold is ionized, one half of the copper is solid, and the remainder is initially above the ionization energy. This suggests there will be an expanding ring of copper that will fragment at later times. Also, the high internal-energy copper and gold that reach the first wall will likely be not only ions, but molecular vapor clusters and droplets after 


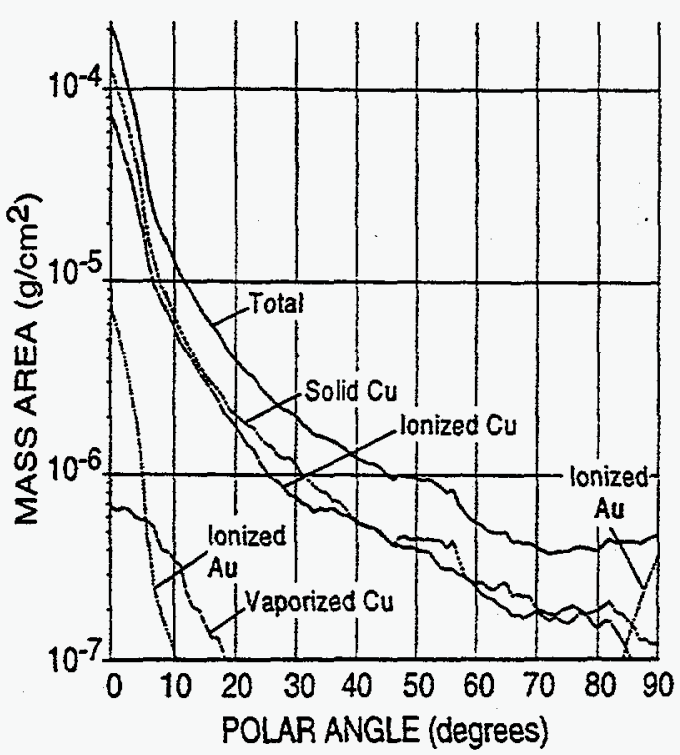

Figure 10. Mass distribution of shrapnel at first wall for no-yield configuration with shine shields.

adiabatic expansion and cooling. The relative damage from this scenario has not yet been assessed.

\section{Description of damage algorithm}

We applied the following damage model to stainless-steel cryonbe shrapnel with results discussed above in Part II. Target material is usually of two types: soft materials such as metals or plastics, and hard materials such as fused silica or ceramics. Soft target material damage consists primarily of a hemispherical plastic crater. Hard target material damage consists of a small plastic crater surrounded by a hemispherical fractured region. A simple algorithm for the damage diameter $D_{S}$ is given by the formula:

$$
D_{S} / L=\beta[\alpha \rho v 2 / Y]^{1 / 3}
$$

where $\beta$ is a proportionality constant that relates the fracture crater diameter to the diameter of the plastic crater, $\mathrm{L}$ is the shrapnel or debris particle characteristic size, $\alpha$ is the fraction of the projectile kinetic energy coupled to the target, $v$ is the impact velocity, $p$ is the density of the shrapnel or debris fragment, and $Y$ is the compressive yield strength of the target material. Impact damage from metallic impactors against brittle target materials with high compressive yield strengths (such as fused silica and $\mathrm{B}_{4} \mathrm{C}$ ) is fundamentally different than damage in soft target materials, because the high strength resists plastic flow and makes only a small plastic crater. However, tensile stresses are produced in the targets, resulting in ring cracks, "Herzian cone cracks" and "lateral cracks" that can excavate surface material and produce shallow craters. The extent of the fractured zone beneath the impactor can be quite large, even though the craters are shallow. The simple algorithm of Eqn. 2 accounts for target strength effects by letting $\beta$ range from 1 for soft targets to a larger value for hard targets. The above formula for metallic particles impacting fused silica, choosing $\alpha \approx 1$ and $\beta \approx$ 10 gives good correlations with NASA data. ${ }^{4}$ In the computations, we used $\beta=8$ for fused silica and $\beta=10$ for $B_{4} C$.

The fused silica data of Ref. 4 produced fracture-dominated damage, with the "spall diameter" $D_{s}$, i.e. the diameter of the fractured region on the impact surface, being much larger than the crater depth. The morphology of the damage is not reported in Ref. 4, but our own observations of fused-silica Nova debris shields showed a hemispherical damage region consistent with our novaculite observations. $^{5}$

The above formula applied to the worst case steel shrapnel $(150 \mu \mathrm{m})$ for a $20 \mathrm{MJ}$ shot produces damage diameters of $0.5 \mathrm{~mm}$ in $\mathrm{B}_{4} \mathrm{C}$ and $1.3 \mathrm{~mm}$ in fused silica. However, the formula is calibrated with hypervelocity data, and may overestimate the damage for the 
slower $(\approx 400 \mathrm{~m} / \mathrm{s})$ worst case shrapnel. Hydrocode simulations and impact experiments are needed to determine the expected range of applicability of the above simple algorithms.

\section{CONCLUSION}

We have made a preliminary estimate of the shrapnel threat to first wall and optics debris shields from stainless steel cryotubes, copper shine shields, and hohlraum material. Computed large relative areal damage arising from micron-size stainless-steel particles may not significantly ablate the first wall $\left(B_{4} C\right)$, but may be sufficient to damage some of the debris shields. However, computed low relative areal damage (100's of large particles) arising from solid shrapnel particles are likely to be the worst case threat at the first wall because deep cratering may cause significant material removal for a thin first wall coating material. Our damage algorithm needs to be calibrated at lower and higher velocities than the $2-7 \mathrm{~km} / \mathrm{s}$ NASA data range because of the significant implications for relative damage.

\footnotetext{
*This work was performed under the auspices of the U.S. Department of Energy by Lawrence Livermore National Laboratory under Contract No. W-7405-Eng-48.
}

\section{REFERENCES}

1. N.F. Mott, "Fragmentation of Shell Cases," Proc. R. Soc. London A, 189, pp. 300-308 (1947).

2. T. G. Trucano, D. E. Grady, and J. M. McGlaun, "Fragmentation Statistics from Eulerian Hydrocode Calculations," Int. J. Impact Eng. 10, Nos. 1-5, Proc. of 1989 Symp. on Hypervelocity Impact, San Antonio, TX, 1214 Dec. 1989 (Pergamon Press, 1990).

3. Jon Larson, private communication: HYDES, "A Radiation Hydrodynamics Code for High Energy-Density Plasma Studies," Cascade Applied Sciences (July 1992).

4. K. S. Edelstein and M. L. Fudge, KSC Corporation, "Penetration and Surface Spalling due to Hypervelocity Impact into Fused Silica", personal communication (1995).

5. D. R. Curran, D. A. Shockey, L. Seaman, and M. Austin, "Mechanisms and Models of Cratering in Earth Media, in Proc. of Symp. on Planetary Cratering Mechanics - Impact and Explosion Cratering, eds. D. J. Roddy, R. O. Pepin, R. B. Merrill (Pergamon Press, 1977).

7 